\title{
MOBILE MULTIWAVELENGTH POLARIZATION RAMAN LIDAR FOR WATER VAPOR, CLOUD AND AEROSOL MEASUREMENT
}

\author{
Songhua Wu ${ }^{1 *}$, Xiaoquan Song ${ }^{1}$, Bingyi Liu ${ }^{1}$, Guangyao Dai ${ }^{1}$, Kailin Zhang ${ }^{1}$, Shengguang Qin ${ }^{1}$, \\ Fei $\mathrm{Gao}^{2}$, Dengxin $\mathrm{Hua}^{2}$
}

1. Ocean Remote Sensing Institute, Ocean University of China, Qingdao 266100, China.

2. Xi'an University of Technology, Xi'an 710048, China.

*Email:wush@ouc.edu.cn

\begin{abstract}
Aiming at the detection of water vapor mixing ratio, particle linear depolarization ratio, extinction coefficient and cloud information, the Water vapor, Cloud and Aerosol Lidar (WVCAL) was developed by the lidar group at Ocean University of China. The Lidar consists of transmitting subsystem, receiving subsystem, data acquisition and controlling subsystem and auxiliary subsystem. These parts were presented and described in this paper. For the measurement of various physical properties, three channels including Raman channel, polarization channel and infrared channel are integrated in this Lidar system. In this paper, the integration and working principle of these channels is introduced in details. Finally, a measurement example which was operated in coastal area-Qingdao, Shandong province, during 2014 is provided.
\end{abstract}

\section{INTRODUCTION}

Water vapor has a great impact on the determination of weather and climate due to its fundamental role in the radiative energy transfer, hydrological cycle, and atmospheric chemistry processes ${ }^{[1]}$. The complexity of atmospheric aerosols resulted from their highly variable particle number concentrations, multimodal size distributions, variable shape characteristics, complex chemical composition and mixing behavior. And the correspondingly large temporal and spatial variability in the aerosol characteristics are the main reasons for the high uncertainties in our quantitative understanding of the role of atmospheric aerosol in environmental, weather, and climate-related processes ${ }^{[2]}$. The Fourth IPCC Assessment Report [3] has identified aerosol radiative forcing and the impact of aerosols on cloud and precipitation processes as one of the major unknowns in our understanding of climate change.

For the detection of the water vapor, two Lidar techniques method are applied: the Differential Absorption Lidar (DIAL) and the Raman Lidar technique. In term of the DIAL, two laser pulses at different wavelengths, called "on-line" and "off-line", respectively, are emitted to the atmosphere ${ }^{[4]}$ for the measurement. In this paper, the Lidar system applied Raman technique. This technique was firstly used by Melfi ${ }^{[5]}$ and Cooney ${ }^{[6]}$ and the profiles of water vapor mixing ratio was retrieved and provided. Rely on its simplicity and ability to measure the profile of water vapor field in the troposphere with high vertical and temporal resolution, the Raman lidar technique has been widely used in meteorology, boundary layer studies, and in climatology ${ }^{[1]}$.

For the detection of the aerosol and cloud, the polarization Lidar technique [7] is a wellestablished method. Ansmann et al. set up a polarization Lidar to distinguish ice clouds from water clouds and to identify layers with ice crystals in mixed-phase clouds ${ }^{[8]}$. In order to study the evolution of contrails Freudenthaler et al. also applied a scanning polarization Lidar in $1996{ }^{[9]}$. The technique has been used to identify the type of polar stratospheric clouds [7] and volcanic ash in the troposphere and stratosphere [10]. The polarization Lidar can also be used to do some research on aerosol profiling ${ }^{[11]}$ and help to classify desert dust from other aerosols such as biomass burning aerosols, fresh smoke, etc. ${ }^{[12]}$.

For the purpose of combined meteorological research and aiming at the detection of water vapor mixing ratio, depolarization ratio extinction and cloud information, the multifunctional WVCAL was developed by the Ocean Remote Sensing Institute at Ocean University of China, Qingdao. The Lidar system was developed from 
June 2012 and was deployed to a field test on July 2013. This Lidar is set up on an optical platform and housed in a weather-proof cabinet. Because of the independence of the entire system, it can be

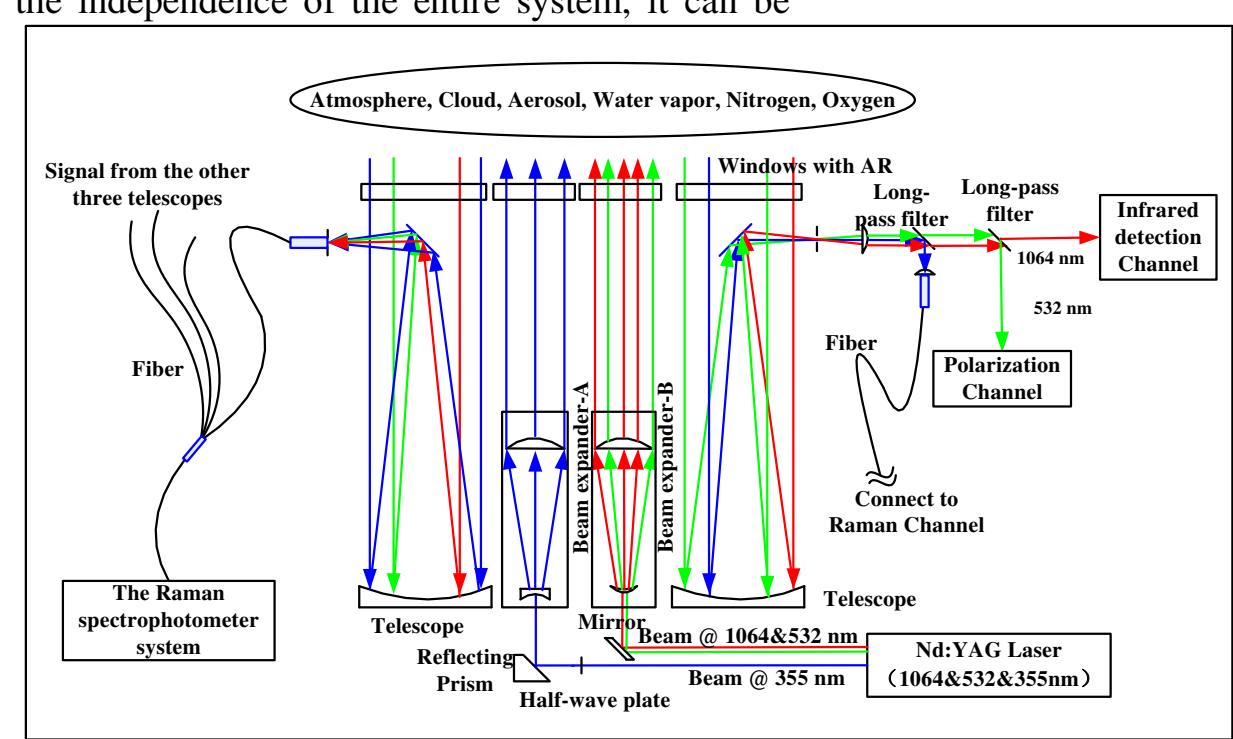

transported and installed easily in the field. The schematic diagram of the whole system is provided in Fig. 1.
Fig.1. Schematic diagram and photos of WVCAL.

2. WATER VAPOR, CLOUD AND AEROSOL

\section{LIDAR}

\subsection{TRANSMITTER}

The laser transmitter, Continuum Powerlite 9030, is a high peak power lamp pump Nd:YAG laser with three wavelengths of $354.7 \mathrm{~nm}, 532 \mathrm{~nm}$ and $1064 \mathrm{~nm}$. And the single pulse energy was $410 \mathrm{~mJ}$, $120 \mathrm{~mJ}$ and $700 \mathrm{~mJ}$, respectively. The wavelength of $354.7 \mathrm{~nm}$ was used for exciting Raman signal of nitrogen and water vapor. Meanwhile the wavelengths of $532 \mathrm{~nm}$ and $1064 \mathrm{~nm}$ were utilized for the detection of Mie and Rayleigh signal. In this system, for purpose of compressing divergence angle and reducing energy cost, two beam expanders were designed. As shown in Fig. 1 , the transmitter system consists of laser transmitter, half-wave plate, reflecting prism, mirror, beam expanders and windows with antireflective coating. The expanded beams with 90$\mathrm{mm}$ diameter transmitted into the atmosphere on an axis closed to the receiver axis.

\subsection{RECEIVER}

After a laser pulse is transmitted to the atmosphere, molecules and particles scatter the light in all directions. A portion of the light is scattered backwards to the lidar. The light is collected by telescopes and transmitted to detection systems. In order to improve the efficiency of receiving, this system deployed four telescopes A, B, C and D (shown in Fig.1.) with the diameter of $300 \mathrm{~mm}$ and the focal length of $1524 \mathrm{~mm}$. The 4 telescopes assembly serve as an equivalent receiver aperture of about $610 \mathrm{~mm}$.

\subsubsection{POLYCHROMATOR OF RAMAN}

\section{CHANNEL}

The optical setup of the polychromator of Raman channel was provided in Fig. 2.

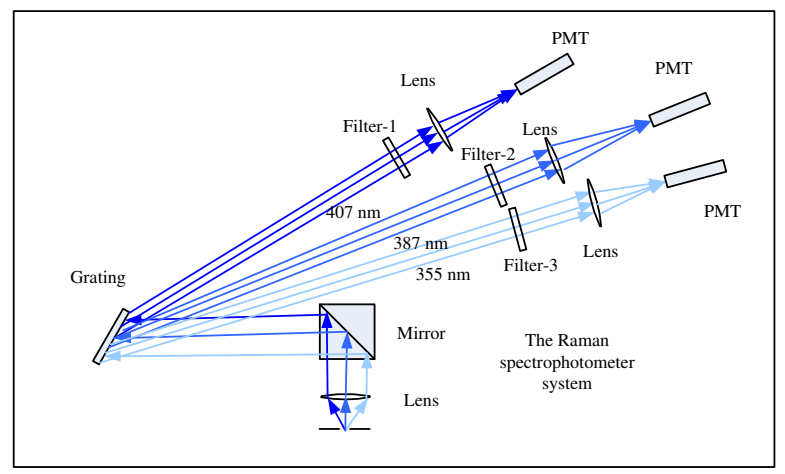

Fig.2. The optical setup of the Raman channel

In order to avoid the interference of the elastic signal, band-pass filter was used. The center wavelength of the filter is $390 \mathrm{~nm}$ and the FWHM is $44.6 \mathrm{~nm}$. The transmission between $370 \mathrm{~nm}$ and 
$410 \mathrm{~nm}$ is bigger than $93 \%$ and the OD is bigger than 5 for light at the wavelength of $354.7 \mathrm{~nm}$ and $532 \mathrm{~nm}$. Four fibers were mounted after the filters to couple the backscatter signal. The core of the fibers was 200 microns and the numerical aperture was 0.22 . After the coupling of fiber, the Raman signal was delivered to the spectrophotometer system and separated as Nitrogen Raman signal and Water vapor Raman signal.

When the signal is coupled to spectrophotometer system, the light is dispersed and then collimated by the convex lens with the focal length of $50.0 \mathrm{~mm}$. After the reflection of the prism, the parallel light arrives at the grating. The groove density of the grating is 1302 line/mm and the blaze wavelength is $400 \mathrm{~nm}$. So far, the elastic signal at $354.7 \mathrm{~nm}$ and Raman signal at $386.7 \mathrm{~nm}$ and $407.5 \mathrm{~nm}$ are separated. Then the filters were used to ensure the purity of each signal. The center wavelengths of the filter-1, filter- 2 and filter-3 are $407.5 \mathrm{~nm} \pm 0.1 \mathrm{~nm}, 386.7 \mathrm{~nm} \pm 0.1 \mathrm{~nm}$ and $354.7 \mathrm{~nm} \pm 0.08 \mathrm{~nm}$, respectively. The FWHM of all filters is $0.5 \mathrm{~nm} \pm 0.10 \mathrm{~nm}$. Peak transmittance is bigger than $50 \%$ and OD is 5 for out of band blocking. After the filtration of filters, the signal was then focused by plano-convex lens with a focal length of $100 \mathrm{~mm}$. Finally, the signals were acquired by the photomultiplier tubes which were mounted at the focal point of plano-convex lens.

\subsubsection{POLARIZATION AND INFRARED CHANNELS}

Considering the high power laser and the strong Rayleigh and Mie scattering, only one telescope B is utilized for the collection of signal in polarization channel and infrared channel. The optical setup is described in Fig. 3.

One adjustable aperture was installed at the focal plane. The field of view can be changed by adjusting the aperture. In this system, the aperture is fixed as $2 \mathrm{~mm}$ and the FOV is determined as $1.3 \mathrm{mrad}$. By utilizing the dichroic long-pass filter1, the elastic signal at $354.7 \mathrm{~nm}$ and Raman signal is reflected and the signal of wavelength longer than $425 \mathrm{~nm}$ transmits through the filter. Similarly, the elastic signal of $532 \mathrm{~nm}$ and 1064 $\mathrm{nm}$ is separated by the dichroic long-pass filter-2. The signal at $1064 \mathrm{~nm}$ is detected by the APD.
The signal at $532 \mathrm{~nm}$ is used to measure the depolarization ratio. The parallel-polarized and cross-polarized signal are separated by the polarizing beam splitter and detected by PMTs respectively.

\subsection{DATA ACQUISITION}

Data acquisition and controlling subsystem consists of PMT, APD, transient recorder and computer. Using PMT and APD, the optical signal are transferred to electrical signal and stored by a Licel transient recorder. The recorder has 6 channels and 2 trigger interface. The channel $\mathrm{C} 1$, $\mathrm{C} 2$ and $\mathrm{C} 3$ were used for Raman channel. $\mathrm{C} 4$ and C5 were utilized for Polarization channel and C6 was for Infrared channel. The trigger signal is from a PIN detector to sense the laser pulse at the laser head.

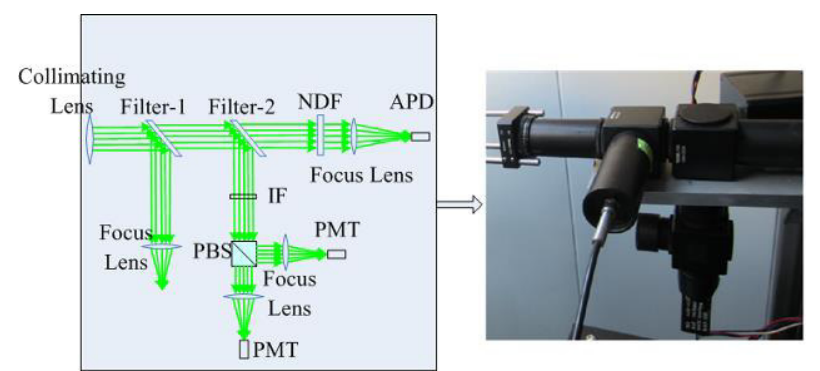

Fig.3. Setup of the polarization and infrared channels

\section{RESULTS / CASE STUDY}

WVCAL has been installed in coastal area and Tibetan plateau for the measurements of atmosphere since 2013. Fig. 4 and Fig. 5 show the result measured on 31 May 2014 in Qingdao.

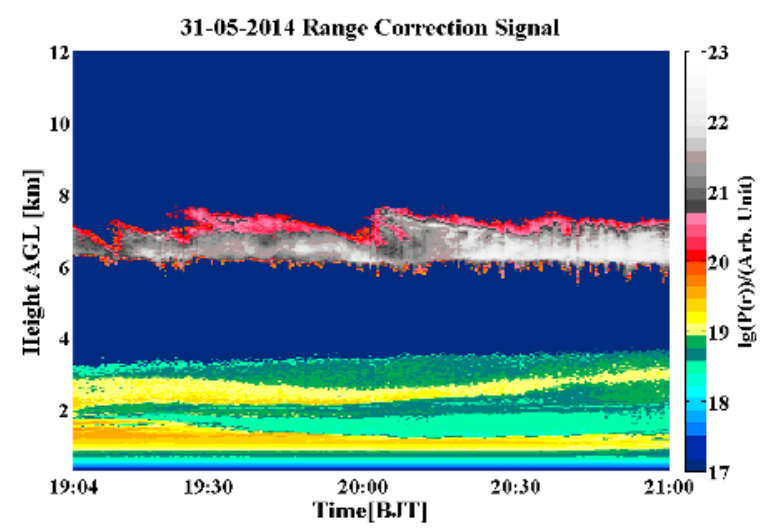

Fig.4. Temporal development of the range-corrected backscatter signal at $532 \mathrm{~nm}$ wavelength 

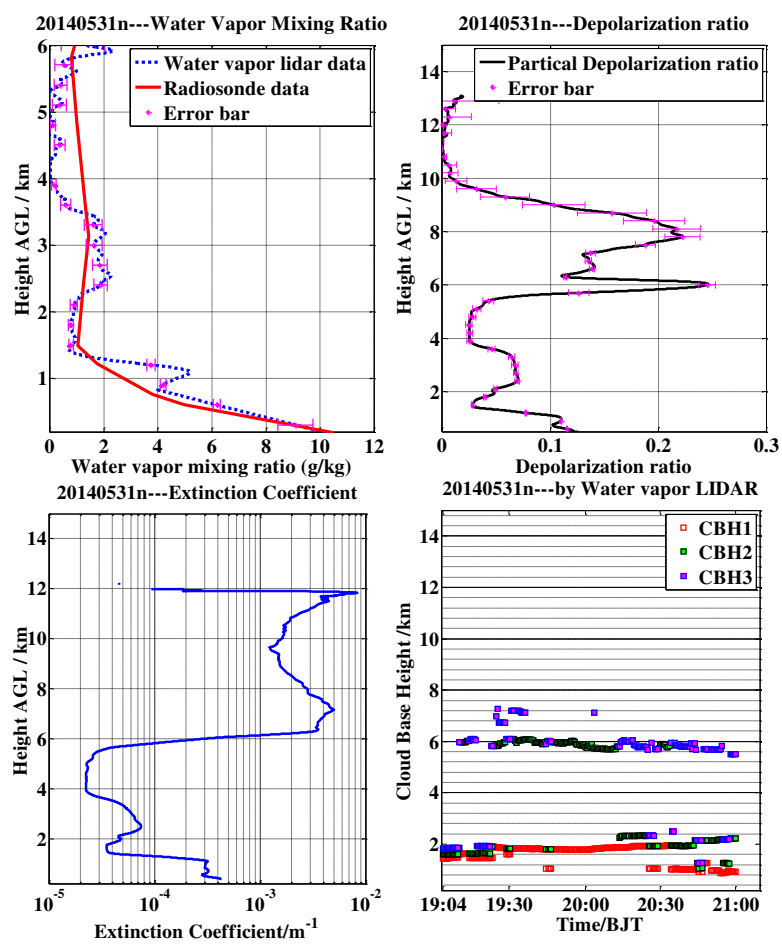

Fig.5. Measurements of water vapor mixing ratio, particle linear depolarization ration, extinction coefficient and cloud base height

\section{ACKNOWLEDGEMENT}

This work was funded by CAMS/LAWS (Chinese Academy of Meteorological Science/Lab oratory of Severe Weather).

\section{REFERENCES}

[1] Dinoev, T., 2009: Automated Raman lidar for day and night operational observation of tropospheric water vapor for meteorological applications(Doctoral dissertation, ÉCOLE POLYTECHNIQUE FÉDÉRALE DE LAUSANNE).

[2] Althausen, D., Engelmann, R., Baars, H., Heese, B., Ansmann, A., Müller, D., \& Komppula, M., 2009: Portable Raman lidar PollyXT for automated profiling of aerosol backscatter, extinction, and depolarization, Journal of Atmospheric and Oceanic Technology, 26(11), 2366-2378.

[3] Forster, P., and Coauthors, 2007: Changes in atmospheric constituents and in radiative forcing, Climate Change 2007: The Physical Science Basis, S. Solomon et al., Eds., Cambridge University Press, 129-234.
[4] Bruneau, D., Quaglia, P., Flamant, C., Meissonnier, M., \& Pelon, J., 2001: Airborne lidar LEANDRE II for water-vapor profiling in the troposphere. I. System description, Applied optics, 40(21), 3450-3461.

[5] Melfi, S. H., Lawrence Jr, J. D., \& McCormick, M. P., 1969: Observation of Raman scattering by water vapor in the atmosphere, Applied Physics Letters, 15(9), 295297.

[6] Cooney, J., 1970: Remote measurements of atmospheric water vapor profiles using the Raman component of laser backscatter, Journal of Applied Meteorology, 9(1), 182-184.

[7] Sassen, K., 2005: Polarization in lidar, Springer New York, 19-42.

[8] Ansmann, A., Tesche, M., Althausen, D., Müller, D., Seifert, P., Freudenthaler, V., \& Dubovik, O., 2008: Influence of Saharan dust on cloud glaciation in southern Morocco during the Saharan Mineral Dust Experiment, Journal of Geophysical Research: Atmospheres (19842012), 113(D4).

[9] Freudenthaler, V., Homburg, F., \& Jäger, H., 1996: Optical parameters of contrails from lidar measurements: linear depolarization, Geophysical research letters, $\mathbf{2 3 ( 2 5 ) , 3 7 1 5 - 3 7 1 8 . ~}$

[10] Sassen, K., Zhu, J., Webley, P., Dean, K., \& Cobb, P., 2007: Volcanic ash plume identification using polarization lidar: Augustine eruption, Alaska, Geophysical Research Letters, 34(8).

[11] Cairo, F., Di Donfrancesco, G., Adriani, A., Pulvirenti, L., \& Fierli, F., 1999: Comparison of various linear depolarization parameters measured by lidar, Applied Optics, 38(21), 4425-4432.

[12] Murayama, T., Müller, D., Wada, K., Shimizu, A., Sekiguchi, M., \& Tsukamoto, T., 2004: Characterization of Asian dust and Siberian smoke with multi- wavelength Raman lidar over Tokyo, Japan in spring 2003.Geophysical Research Letters, 31(23). 